This report was prepared as an account of work sponsored by an agency of the Unitcd States Government. Neither the United States Government nor any agency thereof, nor any of their
employees, makes any warranty, express or implied, or assumes any legal liability or responsiBNL 39768 bility for the accuracy, completeness, or usefulness of any information, apparatus, product, or process disclosed, or represents that its use would not infringe privately owned rights. Reference herein to any specific commercial product, process, or service by trade name, trademark, manufacturer, or otherwise does not necessarily constitute or imply its endorsement, recommendation, or favoring by the United States Government or any agency thereof. The views and opinions of authors expressed herein do not necessarily state or reflect those of the United States Government or any agency thereof.

INFORMAI REPORT

BNL- -39768

DE87 012116

\title{
SUMMARY OF X-RAY RING PERFORMANCE BEFORE THE 1987 SHUTDOWN
}

\author{
H.J. Halama
}

May 11,1987

\author{
Research Supported by the \\ OFFICE OF BASIC ENERGY SCIENCES \\ U.S. Department of Energy \\ Washington, D.C. \\ NATIONAL SYNCHROTRON LIGHT SOURCE
BROOKHAVEN NATIONAL LABORATORY
Associated Universities, Inc.
Under Contract No. DE-AC-76CH00016
}




\section{Introduction}

On February 28, 1987, the X-ray ring was shut down for major modifications. 627 Ampere hours of time integrated current had been accumulated and lifetimes of 25 and 9 hours had been routinely achieved at 50 and $200 \mathrm{~mA}$, respectively. In this paper, I will summarize pressure and lifetime behavior since the first bakeout $^{1}$ in March 1984, when the lifetime at $20 \mathrm{~mA}$ was about 20 minutes. More information can be found in References $1-5$.

\section{Pressure}

From the first bakeout, the pressure in the bending magnets, where most of photon stimulated desorption takes place, decreased by a factor of $\sim 40$. The $\mathrm{CO} / \mathrm{CO}_{2}$ ratio which is significant in beam gas interaction, was lowered by a factor of 5. Most improvement was due to synchrotron radiation clean-up of the vacuum chamber, but some improvement was observed in the pumping speed of distribution pumps (DIP). The pressure in the straight sections was always low, with little influence on the lifetime. After about 60 A-hours, the pressure in the machine became low compared to the rf cavities due to vacuum leaks in the copper seals, rf windows, and welds. The effects on the lifetime became obvious, and after -120 A-hours, rf cavity's pressures ( $>3 \times 10^{-8}$ Torr) became dominant. Various fixes, i.e., cooling the copper seal, vacuum sealant spraying of windows and welds, brought the pressure to an acceptable level (Table I). One remaining problem was a leak in the pump penetration weld of cavity number three, which opened every two to three weeks and lowered the lifetime by. $50 \%$. Luckily, it could always be fixed by vacuum sealant and good lifetime was restored. All problems will be eliminated during the shutdown. Selected pressures in various parts of the ring are tabulated in Table $I$. The following partial pressures in nTorr were calculated for $202 \mathrm{~mA}$ at $620 \mathrm{~A}$-hours:

$$
\begin{aligned}
& \mathrm{H}_{2}(2)=1.3 \\
& \mathrm{CO}(28)=0.7 \\
& \mathrm{~A}(40)=0.1 \\
& \mathrm{CO}_{2}(44)=0.1
\end{aligned}
$$


TABLE I

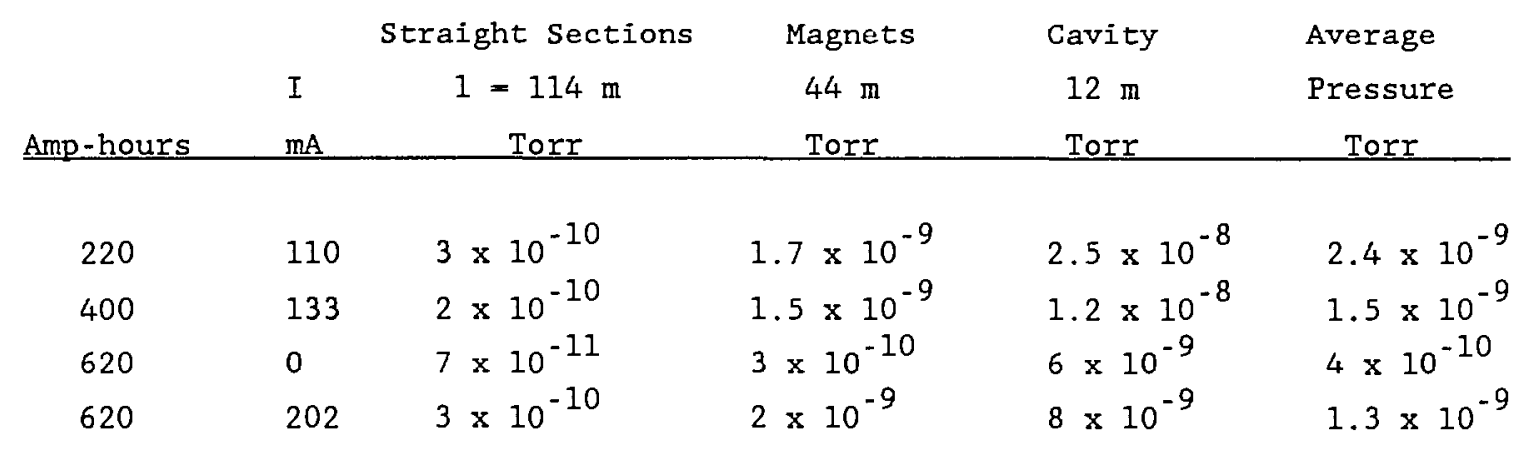

\section{Beam Lifetime}

Knowledge of the partial pressures of residual gas components permits us to calculate the beam lifetime which then can be compared with the measured value shown in Fig. 1. The circulating bear electrons interact both with the nuclei and the electrons of the residual gas atoms, but the total cross sections for nuclear interactions, i.e., Bremsstrahlung and coulomb scattering, dominate the lifetime. Assuming rf acceptance of $1 \%$ (Ref. 2), the Bremsstrahlung lifetime,

$$
\mathrm{T}_{\mathrm{B}}=\frac{3.2 \times 10^{-8} \mathrm{x}_{\mathrm{o}} \text { hours, }}{\mathrm{MP}}
$$

where

$$
\begin{aligned}
& \mathrm{X}_{0}=\text { gas radiation length } \\
& \left.\mathrm{M}=\text { mass } \mathrm{g} \mathrm{cm}^{-2}\right) \\
& \mathrm{P}=\text { pressure (Torr) }
\end{aligned}
$$

Coulomb scattering lifetime ${ }^{7}, \mathrm{~T}_{\mathrm{cs}}$, for $2.53 \mathrm{GeV}$ electrons assuming vertical aperture $\frac{\mathrm{d}}{2}=1 \mathrm{~cm},\langle\beta \mathrm{v}\rangle=10 \mathrm{~m}$ and $\beta \max =28 \mathrm{~m}$

$$
T_{c s}=\frac{5.1 \times 10^{-6}}{z^{2} P} \text { hours }
$$




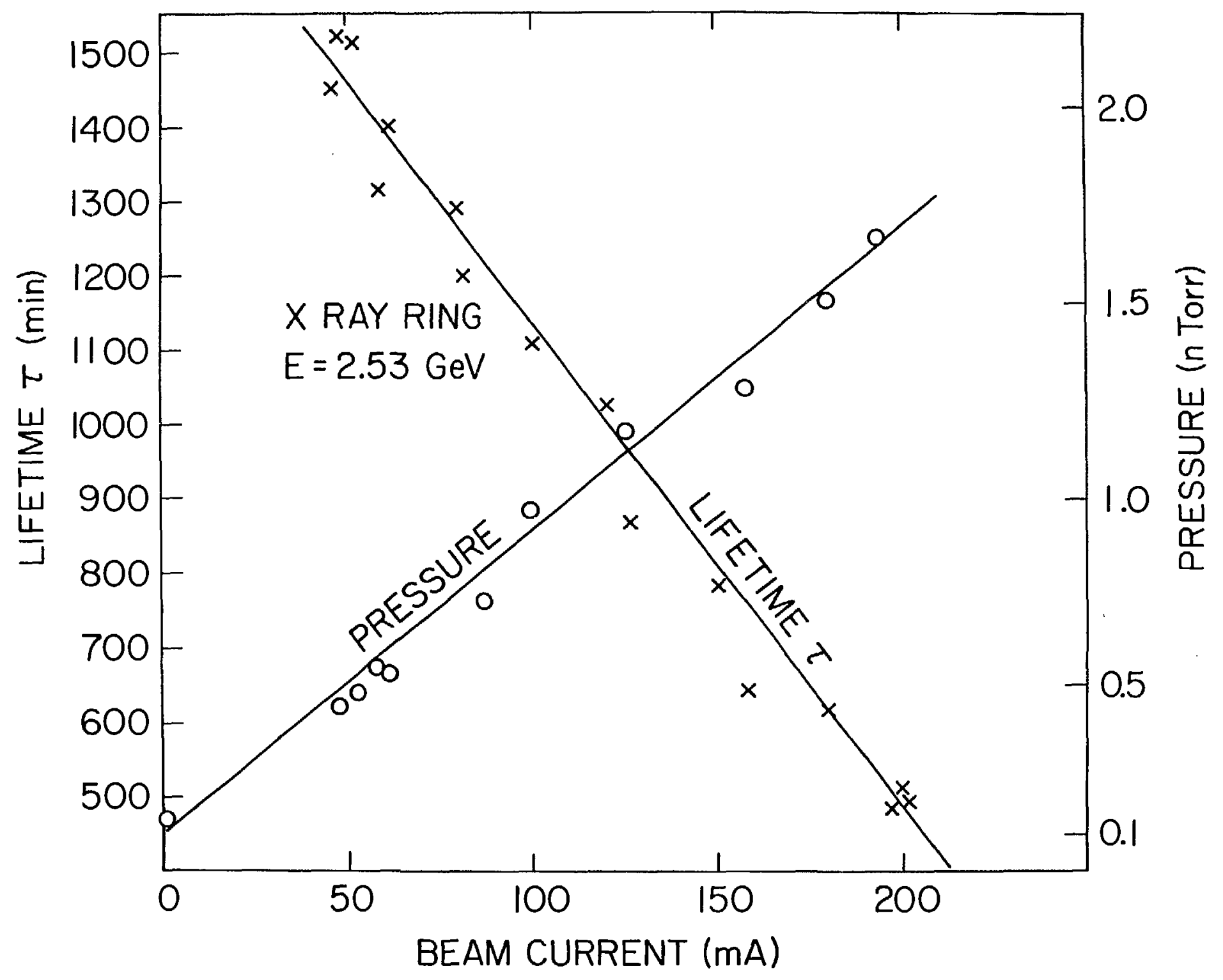

Figure 1 
where $\mathrm{Z}=$ atomic number.

For the scattering on electrons ${ }^{7}$, only the inelastic scattering is of any significance and the resulting lifetime

$$
T_{1 S}=\frac{2 \times 10^{-6}}{2 P} \text { hours }
$$

The lifetimes calculated from partial pressure given in II for bean current of $200 \mathrm{~mA}$ are:

$$
\begin{aligned}
& r_{B}=36 \text { hours } \\
& r_{C S}=38 \text { hours } \\
& r_{1 S}=117 \text { hours. }
\end{aligned}
$$

The resulting total calculated lifetime of 16 hours can be compared with 8.3 hours measured at $200 \mathrm{~mA}$.

The factor of two discrepancy can be due to the following:
a. inaccuracy in measured total and partial pressures
b. different limiting aperture than $2 \mathrm{~cm}$ used in (2)
c. presence of positive ions ${ }^{8}$ trapped in the potential well of the beam chamber in the vacuum.

The ionized residual gas molecules or atoms interact with the beam in the same way as neutral molecules, but are not collected by either the BA gauges or RGAS.

A few selected lifetimes are tabulated in Table II. 
TABLE II

Selected Lifetime

A hours $\quad I(m A)$

$\begin{array}{rrr}11 & 60 & 60 \\ 26 & 90 & 150 \\ 70 & 80 & 300 \\ 220 & 110 & 380 \\ 400 & 130 & 600 \\ 620 & 200 & 500 \\ 620 & 50 & 1500\end{array}$

IV. Distributed Ion Pumps (DIP)

It is a well-known fact that the pumping speed of ion pumps decreases drastically below the $10^{-9}$ Torr range. Since measurement of DIPs dynamic pumping speed is difficult, we have checked their effectiveness by selectively switching off 6,8 , and 16 DIPs and observed the change in lifetime. Table II shows the resulting decrease in lifetime per pump, $\Delta T$, at different stages of $X$-ray ring operation (A-hours). In early stages 10-20 A-hours, little change in lifetime was observed even when all 16 DIPs were switched off. After 620 Ahours, a significant improvement in pumping speed in $10^{-9}$ Torr range was observed.

TABLE III

DIP Performance

\begin{tabular}{rrrrr} 
A-hours & $I(\mathrm{~mA})$ & DIP - off & $\Delta T \%$ & Reference \\
\multirow{2}{*}{10} & 50 & 8 & $<1 \%$ & 1 \\
& 40 & 16 & 0 & 1 \\
\multirow{2}{*}{80} & 70 & 8 & $1 \%$ & 3 \\
& & 16 & $1.1 \%$ & 3 \\
620 & 150 & 6 & $3.4 \%$ &
\end{tabular}




\section{References}

1. H.J. Halama, BNL Report No. BNL-35121 (1984).

2. H.J. Halama, J. Vac. Sci. Technol. A3 (3), 1699 (1985).

3. H.J. Halama, NSLS Technical Notes No. 220 and No. 228 (1985).

4. H.J. Halama, BNL Report No. BNL 37585 (1986).

5. H.J. Halama, C.L. Foerster, and T. Kobari, J. Vac. Sci. Technol. A5 (3) (in press).

6. J. Kouptsidis and A.G. Mathewson, DESY Report No. $76 / 49$ (1976).

7. J. LeDuff, Nucl. Instr. and Meth. A239, 83 (1985).

8. Y. Miyahara, University of Tokyo, to be published in J. Vac. Sci. Technol. and private communication. 